\title{
The Role Descriptions of Triage Nurse in Emergency Department: A Delphi Study
}

\author{
Mohsen Ebrahimi, ${ }^{1}$ Amir Mirhaghi, ${ }^{2}$ Reza Mazlom, ${ }^{2}$ Abbas Heydari, ${ }^{2}$ \\ Asra Nassehi, ${ }^{3}$ and Mojtaba Jafari ${ }^{4}$ \\ ${ }^{1}$ Department of Emergency Medicine, Imam Reza Hospital, Mashhad University of Medical Sciences, Mashhad 9137913316, Iran \\ ${ }^{2}$ Evidence-Based Caring Research Center, Department of Medical-Surgical Nursing, School of Nursing and Midwifery, \\ Mashhad University of Medical Sciences, Mashhad 9137913199, Iran \\ ${ }^{3}$ Research Center for Health Services Management, Institute for Futures Studies in Health, Kerman University of Medical Sciences, \\ Kerman 7616913555, Iran \\ ${ }^{4}$ Department of Medical-Surgical Nursing, Faculty of Nursing and Midwifery, Bam University of Medical Sciences, \\ Khalije Fars Boulevard, Bam, Kerman 7661771967, Iran
}

Correspondence should be addressed to Amir Mirhaghi; mirhaghia@mums.ac.ir

Received 2 December 2015; Accepted 19 April 2016

Academic Editor: Toomas Timpka

Copyright (C) 2016 Mohsen Ebrahimi et al. This is an open access article distributed under the Creative Commons Attribution License, which permits unrestricted use, distribution, and reproduction in any medium, provided the original work is properly cited.

Background. Triage nurses play a pivotal role in the emergency department. However some researchers have attempted to expand triage nurse's role; remarkable discrepancies exist among scholarly communities. The aim was to develop a role description of triage nurse relying on the experts. Methods. A modified Delphi study consisting of 3 rounds was performed from March to October 2014. In the first round, an extensive review of the literature was conducted. Expert selection was conducted through a purposeful sample of 38 emergency medicine experts. Results. Response rates for the second and third rounds were $37 \%$ and $58 \%$. Average age of panelists was $(38.42 \pm 5.94)$ years. Thirty-nine out of 54 items reached to the final round. Prioritizing had the higher agreement rate and least agreement on triage related interventions. Conclusion. Triage nursing as a relatively new role for nurses needs significant development to be practiced. Comprehensive educational programs and developmental research are required to support diagnostic and therapeutic interventions in triage practice by nurses.

\section{Introduction}

Triage is defined as prioritizing or sorting the patients for the care and treatment that is due to shortage of the necessary resources in the emergency department (ED) [1]. Several studies have focused on the validity and reliability of triage scales $[2,3]$ and assessed agreement between nurses and physicians $[4,5]$. Factors which affect triage practice were also studied [6]. Some studies have explored triage nurse's daily job activities as well as how they decided to allocate patients to triage categories $[7,8]$ but researchers rarely try to describe triage nurse job.

In response to overcrowding, some studies tried to explain increased efficiency of triage process regarding expanding physician and nurses roles in the triage room [912] in which placing a senior emergency physician with the triage nurse reduced waiting times for nonemergent cases [10] so the concept of team triage has been evolved. Of course, it is clear that it is not possible for most EDs to have a senior emergency physician in the triage room. In order to customize patient flow more consciously and despite high satisfaction among staff and patient, initiating X-rays by triage nurses did not reduce transit times for patients with limb injuries in ED [13]. In contrast, some studies have indicated triage nurse ordering seems to be an effective intervention to reduce ED length of stay in patients with injuries [11]. Therefore findings revealed that triage nurses' role is challenging in the ED. 
Role description is designed to guarantee the best possible performance by employees. In this way, the emergency associations have tried to develop position statement to define triage nurse role in order to secure patient safety in triage room. All associations have indicated that triage must be performed at least by a registered nurse. Despite remarkable discrepancies among statements, triage nurses are required to perform prioritizing of the patient care, take educational programs, and provide a safe environment as well as interpersonal qualifications needed to fulfill this role [1417]. However, only the Emergency Nurses Association (ENA) has comprehensively indicated several educational programs (CPR, ALS, ENPC, TNCC, GENE, CEN, and CPEN) in addition to other triage educational programs [14]. Furthermore interpersonal qualifications including interpersonal, interdisciplinary, critical thinking, and communication skills as well as accurate decision making have been stated by several emergency associations [14-17]. However advanced practice nursing roles have been recommended to improve patient flow through the ED [18]; advanced practice nursing roles have been rarely addressed by emergency associations. Even the Royal College of Nursing has indicated triage related interventions such as administrating analgesia [17], so it concluded that role description of triage nurse suffered from lack of an integrated approach. There is a strong possibility that it also affects the reliability and validity of decisions among triage nurses in the ED.

Delphi method as an iterative process is to explore implicit information leading to differing judgments and search information which may generate a consensus on behalf of the respondent group [19]. It has been employed by many nurse researchers in a wide variety of studies [20]. So Delphi method was used to develop a role description of triage nurse relying on the emergency medicine experts.

\section{Materials and Methods}

A modified Delphi study consisting of 3 rounds was performed from March to October 2014. Anonymity, iteration with controlled feedback, and statistical consensus were included in the Delphi method [20].

The study was approved by the Research Ethics Committee at the Mashhad University of Medical Sciences. Confidentiality and anonymity of the experts' participation were secured. It was clearly defined that there is no obligation for them to reply to the questionnaire.

In the first round, an extensive review of the literature was conducted [21]. Main question of the study was, what are the attributes of the triage nurse role? Electronic databases were searched from inception to February 2014. Medline (Pubmed) and Scopus were searched without any additional filter. The keywords searched alone and in combination were "triage", "nurse", "role", "Job”, "analysis", "position", and "statement". Titles and abstracts were reviewed to identify the relevant studies in the primary review. In the secondary review, articles were included only if the study defined role of the triage nurse. Studies were excluded if they have not been approved by emergency associations or colleges. Extended review was conducted to retrieve additional studies using search engines. Data were extracted from relevant articles based on researchers' agreement to identify attributes of the triage nurse contributing to the generation of items pool to compose the primary questionnaire. Researchers continued to collect data until they reach a point of data saturation. In the first round, selecting items for primary questionnaire were based on the three researchers' consensus. Each researcher rated relevancy of items using Likert-type scale items (5: completely, 4: mostly, 3: moderately, 2: slightly, and 1: not at all). Average of rated responses was reported for each item (Figure 1).

Expert selection was conducted through a purposeful sample of 38 emergency medicine experts and emergency nursing scholars. They were involved in emergency medicine and emergency nursing, so they were invited to take part. Experts were ED directors and physicians or nurses who have known interest in triage practice and research. Potential contributors were retrieved from triage committees and associations, authors of triage publications, and published articles. All contributors were individually communicated by email.

In the second round, an initial task list of triage nurse role was sent to the expert panelists in May 2014. Fifty-four items were included in the questionnaire. Items were related to the domains including basics, ethics, triage assessment, decision making, informing, competencies, environment, and documentation. Expert opinions on proposed tasks were obtained by responses on a 5-point Likert scale (1: strongly disagree, 2: disagree, 3: undecided, 4: agree, and 5: strongly agree). Participants were asked to comment on any items as needed. Completed questionnaires were analyzed and agreement on each item was reported.

In the third round, a modified questionnaire was sent to the expert panelists in July 2014. Participants were informed about the opinion of other colleagues as well as theirs. Both second- and third-round questionnaires were sent to all the individuals regardless of their contributions in the second round. Two reminders sent to the participants who did not reply. Reminders were sent at two-week interval.

Proportions and percentages were calculated for ordinal data of Likert-type response scale. The data of each iterative round was analyzed using MS Excel (2007). Only strongly agree and agree responses to items were assumed as approved items [22]. Each approved item which obtained a consensus level of $80 \%$ was identified for the next phase. The feedback for each round contained statistical result from the former round, which included the consensus level reached for each item.

\section{Results}

Six expert panelists of 38 were female. Average age of panelists was $(38.42 \pm 5.94)$. Most participants had a medical degree in emergency medicine. All participants had an affiliation with a university hospital.

3.1. Round One. Twenty-three studies were chosen among 353 articles which have been retrieved through searching databases and 7 were included in the final analysis. 


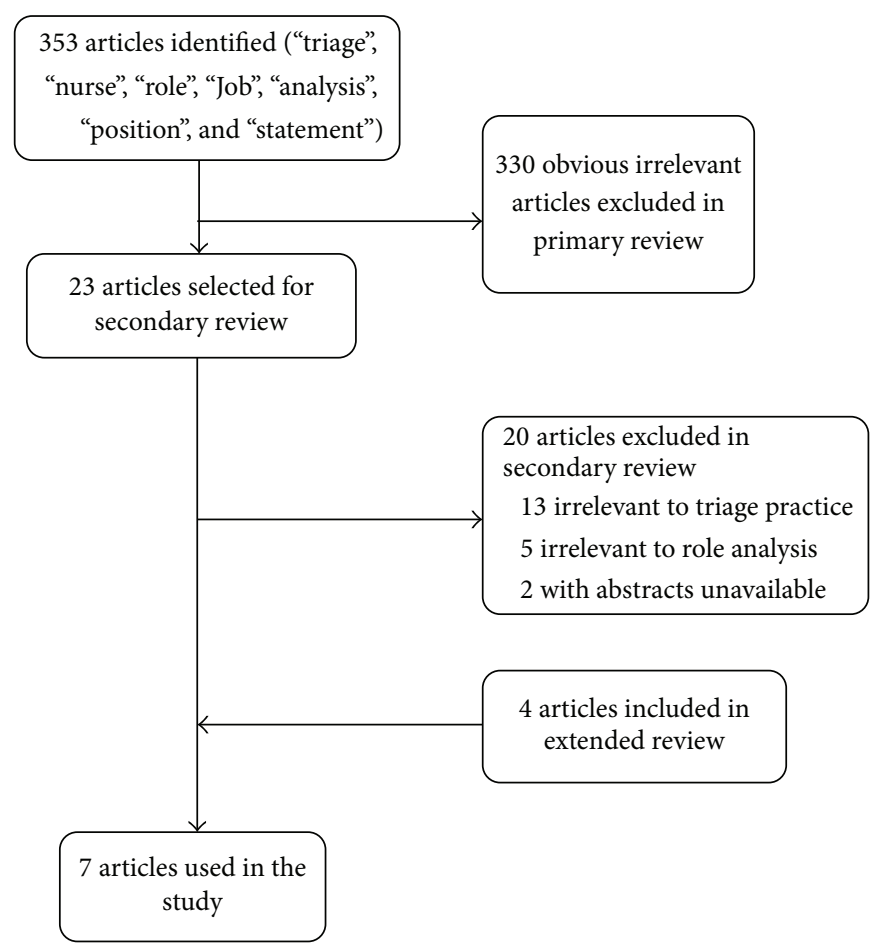

FIGURE 1: Study selection process.

Sixty-two items were primarily extracted from the final studies and redundant items were merged together, remaining 54 items in the list (Table 1).

3.2. Round Two. Response rate for the second round was $31 \%$ $(14 / 38)$. The number of items which remained in the end of the round was 43 (80\%). Forty-one percent (22/54) of items achieved a complete consensus. 11 items were excluded since they did not reach a consensus level of $80 \%$. Excluded items included legal issues (triage nurse responsibility for patient status and handing over level I patients to the emergency nurses and reconsidering their decisions); informing issues (informing patients about assigned triage level, their condition, outcomes, and potential care and treatment); ethical issues (empathy and tactfulness characteristics); and other issues (mandatory research participation and responsibility for triage room facilities and condition). Four new items were proposed including diagnostic and therapeutic interventions and added to the next round questionnaire (49 items). Four (7\%) items were suggested to be edited lightly by participants (Table 1).

3.3. Round Three. Response rate for third round was $58 \%$ $(22 / 38)$. The number of items which reached to the end of the round was 43 (88\%). Fifty-five percent (27/49) of items achieved a complete consensus. Seven items were excluded since they did not reach a consensus level of $80 \%$. Excluded items included ethical issues (having patience); competency issues (continuing education); and other issues (diagnostic and therapeutic intervention and physician participations).
No item was proposed for the next round questionnaire (39 items) (Table 1).

\section{Discussion}

Triage related interventions still need extensive development to be reliable enough to practice by triage nurses. Our results did not reveal substantial agreement on triage nurse ordering (Table 1) which is consistent with most position statements on triage nurse role [14-17]. However some studies supported diagnostic interventions by triage nurse as well as advanced practice nursing roles [11, 18, 23]; scientific evidence is limited to ensure significant impact on patient flow in the emergency department and efficiency [24]. Despite this inconsistency, expanding the role of triage nurse caused significant increases in nurses' satisfaction [12]. Further studies are needed to develop more clarification of the contextual factors related to the interventions and investigate the impact of them on the ED measures as the next generation of triage studies. Educational preparation and organized teamwork are essentially required for advanced practice role to be successfully implemented [25]. So prioritizing care and introducing fast track for patients were known as the fundamental role for triage nurse which is unique to the emergency department and associated with desirable outcomes [24].

There is broad consensus that nurses are accountable for ensuring safe triage practices [14-17]. Our results did not indicate a broad consensus among clinicians that physicians routinely perform triage in ED (Table 1). Several studies demonstrated that intelligent use of physicians in triage causes substantial improvement in ED patient flow and 
TABLE 1: Participants' responses to the questionnaire.

\begin{tabular}{|c|c|c|c|}
\hline Items & $\begin{array}{l}\text { First round } \% \\
\quad(n=3)\end{array}$ & $\begin{array}{l}\text { Second round } \% \\
\quad(n=14)\end{array}$ & $\begin{array}{l}\text { Third round } \% \\
\quad(n=22)\end{array}$ \\
\hline Prioritizing patients must be based on patients' acuity & 100 & 86 & 91 \\
\hline $\begin{array}{l}\text { Prioritizing patients must not be affected by ED overcrowding and } \\
\text { financial status of patients }\end{array}$ & 66 & 86 & 100 \\
\hline Triage decisions must be made based on evidence & 100 & 100 & 100 \\
\hline Triage decisions must be made based on reliable and valid algorithm & 100 & 100 & 100 \\
\hline $\begin{array}{l}\text { Triage nurse is responsible for patients status until the first physician } \\
\text { visit }\end{array}$ & 66 & $71^{*}$ & - \\
\hline Patients must be assigned to the triage levels based on relevant acuity & 100 & 100 & 100 \\
\hline Nurses are not allowed to reject patients from ED & 100 & 93 & 95 \\
\hline Nurses must be committed to the patient bill of rights & 100 & 100 & 100 \\
\hline Nurses must identify themselves to patients & 100 & 100 & 100 \\
\hline Nurses must have empathy toward patients & 66 & $64^{*}$ & - \\
\hline Patients' culture and value must be respected by triage nurses & 100 & 93 & 100 \\
\hline Triage nurses must manage ethical conflict in triage decisions & 100 & 93 & 91 \\
\hline Triage nurses must manage aggressive patients effectively & 100 & 93 & 86 \\
\hline Triage nurses must have patience & 100 & 100 & $77^{*}$ \\
\hline Triage nurses must handle conflict in a tactful manner & 100 & $57^{*}$ & - \\
\hline Triage nurses must have interpersonal skills & 100 & 100 & 100 \\
\hline Triage nurses must perform the first assessment in the ED & 100 & 100 & 100 \\
\hline Triage nurses must estimate life-threatening risk of chief complaints & 100 & 100 & 100 \\
\hline $\begin{array}{l}\text { Except in life-threatening conditions, triage nurses must observe } \\
\text { patients at least in } 2 \text { minutes }\end{array}$ & 66 & 86 & 82 \\
\hline $\begin{array}{l}\text { Triage nurses must prioritize patients based on assessing respirations, } \\
\text { pulse rate, blood pressure, temperature, } \mathrm{O}_{2} \text { saturation, and other } \\
\text { diagnostic measures }\end{array}$ & 66 & 93 & 100 \\
\hline Patients should be reassessed when needed & 100 & 100 & 100 \\
\hline Triage decisions must be recorded & 100 & 100 & 100 \\
\hline $\begin{array}{l}\text { Triage nurses must follow organization's guidelines during decision } \\
\text { making }\end{array}$ & 66 & 86 & 90 \\
\hline $\begin{array}{l}\text { In case of doubt, triage nurses must consult with attending physician } \\
\text { or head nurse }\end{array}$ & 100 & 93 & 100 \\
\hline $\begin{array}{l}\text { In case of doubt, triage nurses must assign patient to the higher level } \\
\text { of acuity }\end{array}$ & 100 & 100 & 100 \\
\hline $\begin{array}{l}\text { Triage nurses must reconsider their decisions if requested from } \\
\text { medical directors }\end{array}$ & 100 & $64^{*}$ & - \\
\hline Level I patients must be directed to the CPR room promptly & 100 & 93 & 100 \\
\hline Level I patients must be handed over to the emergency nurses & 100 & $71^{*}$ & - \\
\hline $\begin{array}{l}\text { Patients must be informed in either verbal or written way regarding } \\
\text { their assigned triage level }\end{array}$ & 66 & $64^{*}$ & - \\
\hline $\begin{array}{l}\text { Patients must be informed that they must inform triage nurses in case } \\
\text { of deterioration in their health status }\end{array}$ & 100 & 86 & $77^{*}$ \\
\hline Triage nurses must explain waiting time to the first visit & 66 & 93 & 82 \\
\hline $\begin{array}{l}\text { Triage nurses must explain necessary information relating to the } \\
\text { patient condition }\end{array}$ & 100 & $71^{*}$ & - \\
\hline $\begin{array}{l}\text { Triage nurses must explain necessary information relating to } \\
\text { alternative facilities for care and treatment }\end{array}$ & 100 & $71^{*}$ & - \\
\hline Triage nurses must be aware of alternative health care facilities & 100 & 93 & 91 \\
\hline Triage nurses must have a minimum degree of BS in nursing & 100 & 93 & 82 \\
\hline Triage nurses must have a minimum 2-year experience in ED & 100 & 100 & 100 \\
\hline $\begin{array}{l}\text { Triage nurses must have a minimum } 40 \text {-hour educational courses } \\
\text { annually }\end{array}$ & 66 & 100 & $73^{*}$ \\
\hline
\end{tabular}


TABle 1: Continued.

\begin{tabular}{|c|c|c|c|}
\hline Items & $\begin{array}{l}\text { First round\% } \\
\quad(n=3)\end{array}$ & $\begin{array}{l}\text { Second round\% } \\
\quad(n=14)\end{array}$ & $\begin{array}{l}\text { Third round } \% \\
\quad(n=22)\end{array}$ \\
\hline Nurses must be knowledgeable about clinical semiology & 100 & 100 & 100 \\
\hline $\begin{array}{l}\text { Nurses must be knowledgeable about advanced and basic adult life } \\
\text { support }\end{array}$ & 100 & 86 & 82 \\
\hline Nurses must be knowledgeable about emergencies & 100 & 100 & 100 \\
\hline $\begin{array}{l}\text { Nurses must be knowledgeable about gynecological, maternal, } \\
\text { neonatal, children, and geriatrics emergencies }\end{array}$ & 100 & 100 & 100 \\
\hline Nurses must be knowledgeable about outcome of disease & 100 & $71^{*}$ & - \\
\hline Nurses must participate in at least one emergency research & 100 & $50^{*}$ & - \\
\hline $\begin{array}{l}\text { Triage room must be somewhere between emergency department and } \\
\text { security room }\end{array}$ & 100 & 100 & 100 \\
\hline Triage room must be easily recognizable for patients & 100 & 100 & 100 \\
\hline Triage room must have an appropriate view on entrance of ED & 100 & 100 & 100 \\
\hline $\begin{array}{l}\text { Triage room must be accessible for ambulances, stretchers, and } \\
\text { wheelchairs }\end{array}$ & 100 & 100 & 100 \\
\hline Triage room must be at least 12 square meters & 100 & $79^{*}$ & - \\
\hline $\begin{array}{l}\text { Triage room must be equipped for professionals standard infection } \\
\text { control precautions }\end{array}$ & 100 & 93 & 82 \\
\hline Triage room must have alarm, telephone, and closed-circuit television & 100 & 100 & 100 \\
\hline Triage nurses are responsible for facilities of triage room & 100 & $79^{*}$ & - \\
\hline $\begin{array}{l}\text { Triage nurses are not permitted to leave the triage room, except for } \\
\text { handing over level I patients }\end{array}$ & 100 & 86 & $77^{*}$ \\
\hline Triage nurses must document triage assignments & 100 & 93 & 100 \\
\hline Triage nurses must report daily and monthly statistics of triage & 100 & 93 & 100 \\
\hline $\begin{array}{l}\text { Triage nurses must consider hospital facilities when assigning } \\
\text { patients to triage level }\end{array}$ & - & Proposed & 82 \\
\hline Diagnostic related interventions must be performed by triage nurses & - & Proposed & $41^{*}$ \\
\hline Therapeutic related interventions must be performed by triage nurses & - & Proposed & $55^{*}$ \\
\hline Physician must participate in prioritizing of patients in triage room & - & Proposed & $77^{*}$ \\
\hline
\end{tabular}

${ }^{*}$ Less than consensus level of $80 \%$.

results in shorter length of stay especially in overcrowded conditions in the ED $[24,26]$. Some studies suggested that emergency nurse practitioners as an optimal choice have greater impact on quality measures and financial indices in $\operatorname{ED}[12,27]$. Comparison between the nurse practitioner and general practitioners demonstrated that the nurse practitioner can deal with patients effectively $[12,28]$ and they can be assumed as superb candidates for expanded and extended role [29].

A limitation of the study is that the modified Delphi method was used. Several modifications of the original Delphi method have been described in the literature [30] and standardized definitions of these modifications are not available. Besides, panelists did not generally mention rationale in case of disagreement.

\section{Conclusions}

Triage nursing as a relatively new role for nurses is a challenging role in a dynamic environment which needs significant development to be practiced. Prioritizing is defined as the pivotal role for triage nurse. Comprehensive educational programs and developmental research are required to support diagnostic and therapeutic interventions in triage practice by nurses.

\section{Appendix}

\section{Search Strategies}

Primary Search. Primary search included the following: ("triage" [MeSH Terms] OR "triage" [All Fields]) AND ("nurse's role" [MeSH Terms] OR ("nurse's" [All Fields] AND "role" [All Fields]) OR "nurse's role" [All Fields] OR ("nurse" [All Fields] AND "role" [All Fields]) OR "nurse role" [All Fields]).

\section{Competing Interests}

The authors declare that there are no competing interests. 


\section{Acknowledgments}

Many thanks are due to Dr. Mojtaba Jafari for his help. Also the authors gratefully acknowledge all participants for their cooperation.

\section{References}

[1] A. Mirhaghi, H. Kooshiar, H. Esmaeili, and M. Ebrahimi, "Outcomes for emergency severity index triage implementation in the emergency department," Journal of Clinical and Diagnostic Research, vol. 9, no. 4, pp. OC04-OC07, 2015.

[2] N. Farrohknia, M. Castrén, A. Ehrenberg et al., "Emergency department triage scales and their components: a systematic review of the scientific evidence," Scandinavian Journal of Trauma, Resuscitation and Emergency Medicine, vol. 19, article 42, 2011.

[3] A. Mirhaghi, A. Heydari, R. Mazlom, and M. Ebrahimi, "The reliability of the canadian triage and acuity scale: meta-analysis," North American Journal of Medical Sciences, vol. 7, no. 7, pp. 299-305, 2015.

[4] A. R. Allen, M. J. Spittal, C. Nicolas, E. Oakley, and G. L. Freed, "Accuracy and interrater reliability of paediatric emergency department triage," Emergency Medicine Australasia, vol. 27, no. 5, pp. 447-452, 2015.

[5] M. Ebrahimi, A. Heydari, R. Mazlom, and A. Mirhaghi, "Reliability of the Australasian triage scale: meta-analysis," World Journal of Emergency Medicine, vol. 6, no. 2, pp. 94-99, 2015.

[6] A.-K. Andersson, M. Omberg, and M. Svedlund, "Triage in the emergency department-a qualitative study of the factors which nurses consider when making decisions," Nursing in Critical Care, vol. 11, no. 3, pp. 136-145, 2006.

[7] M. F. Gerdtz and T. K. Bucknall, “Triage nurses' clinical decision making. An observational study of urgency assessment," Journal of Advanced Nursing, vol. 35, no. 4, pp. 550-561, 2001.

[8] M. Fry and G. Burr, "Current triage practice and influences affecting clinical decision-making in emergency departments in NSW, Australia," Accident and Emergency Nursing, vol. 9, no. 4, pp. 227-234, 2001.

[9] B. R. Holroyd, M. J. Bullard, K. Latoszek et al., "Impact of a triage liaison physician on emergency department overcrowding and throughput: a randomized controlled trial," Academic Emergency Medicine, vol. 14, no. 8, pp. 702-708, 2007.

[10] J. P. Travers and F. C. Y. Lee, "Avoiding prolonged waiting time during busy periods in the emergency department: is there a role for the senior emergency physician in triage?" European Journal of Emergency Medicine, vol. 13, no. 6, pp. 342-348, 2006.

[11] B. H. Rowe, C. Villa-Roel, X. Guo et al., "The role of triage nurse ordering on mitigating overcrowding in emergency departments: a systematic review," Academic Emergency Medicine, vol. 18, no. 12, pp. 1349-1357, 2011.

[12] S. Reveley, "The role of the triage nurse practitioner in general medical practice: an analysis of the role," Journal of Advanced Nursing, vol. 28, no. 3, pp. 584-591, 1998.

[13] W. Parris, S. McCarthy, A.-M. Kelly, and S. Richardson, "Do triage nurse-initiated X-rays for limb injuries reduce patient transit time?" Accident and Emergency Nursing, vol. 5, no. 1, pp. 14-15, 1997.

[14] The Emergncy Nurses Association, Triage Qualifications: Position Statement, ENA, Des Plaines, Ill, USA, 2011.
[15] The College of Emergency Nursing Australasia, Triage Nurse: Position Statement, CENA, Surrey Hills, Australia, 2009.

[16] The National Emergency Nurses Affiliation, Role of the Triage Registered Nurse, ON NENA, Pembroke Pines, Fla, USA, 2011.

[17] The College of Emergency Medicine Clinical Effectiveness Committee, Emergency Nurse Consultant Association, Faculty of Emergency Nursing, Royal College of Nursing Emergency Care Association, Triage Position Statement, CEM, London, UK, 2011.

[18] E. Elder, A. N. B. Johnston, and J. Crilly, "Review article: systematic review of three key strategies designed to improve patient flow through the emergency department," Emergency Medicine Australasia, vol. 27, no. 5, pp. 394-404, 2015.

[19] F. Hasson, S. Keeney, and H. McKenna, "Research guidelines for the Delphi survey technique," Journal of Advanced Nursing, vol. 32, no. 4, pp. 1008-1015, 2000.

[20] S. Keeney, F. Hasson, and H. P. McKenna, "A critical review of the Delphi technique as a research methodology for nursing," International Journal of Nursing Studies, vol. 38, no. 2, pp. 195200, 2001.

[21] J. Stewart, C. O’Halloran, P. Harrigan, J. A. Spencer, J. R. Barton, and S. J. Singleton, "Identifying appropriate tasks for the preregistration year: modified Delphi technique," British Medical Journal, vol. 319, no. 7204, pp. 224-229, 1999.

[22] D. F. Polit, C. T. Beck, and S. V. Owen, "Focus on research methods: Is the CVI an acceptable indicator of content validity? Appraisal and recommendations," Research in Nursing and Health, vol. 30, no. 4, pp. 459-467, 2007.

[23] D. Pringle, "Expanding nurses' scope of practice," Nursing leadership, vol. 22, no. 2, pp. 1-4, 2009.

[24] S. Oredsson, H. Jonsson, J. Rognes et al., "A systematic review of triage-related interventions to improve patient flow in emergency departments," Scandinavian Journal of Trauma, Resuscitation and Emergency Medicine, vol. 19, article 43, 2011.

[25] J. Considine, E. Lucas, R. Payne, M. Kropman, H. E. Stergiou, and $\mathrm{H}$. Chiu, "Analysis of three advanced practice roles in emergency nursing," Australasian Emergency Nursing Journal, vol. 15, no. 4, pp. 219-228, 2012.

[26] L. Burström, M. Nordberg, G. Örnung et al., "Physician-led team triage based on lean principles may be superior for efficiency and quality? A comparison of three emergency departments with different triage models," Scandinavian Journal of Trauma, Resuscitation and Emergency Medicine, vol. 20, article 57, 2012.

[27] D. Bahena and C. Andreoni, "Provider in triage: is this a place for nurse practitioners?" Advanced Emergency Nursing Journal, vol. 35, no. 4, pp. 332-343, 2013.

[28] B. L. Lim, Z. R. Eunice Tay, A. Vasu, and W. J. Kenneth Heng, "Comparing triage evaluation of adult dyspneic patients between emergency nurses and doctors using simulated scenarios," International Emergency Nursing, vol. 21, no. 2, pp. 103-112, 2013.

[29] M. Griffin and V. Melby, "Developing an advanced nurse practitioner service in emergency care: attitudes of nurses and doctors," Journal of Advanced Nursing, vol. 56, no. 3, pp. 292301, 2006.

[30] R. Boulkedid, H. Abdoul, M. Loustau, O. Sibony, and C. Alberti, "Using and reporting the Delphi method for selecting healthcare quality indicators: a systematic review," PLoS ONE, vol. 6, no. 6, Article ID e20476, 2011. 


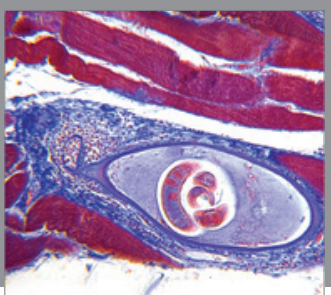

Gastroenterology

Research and Practice
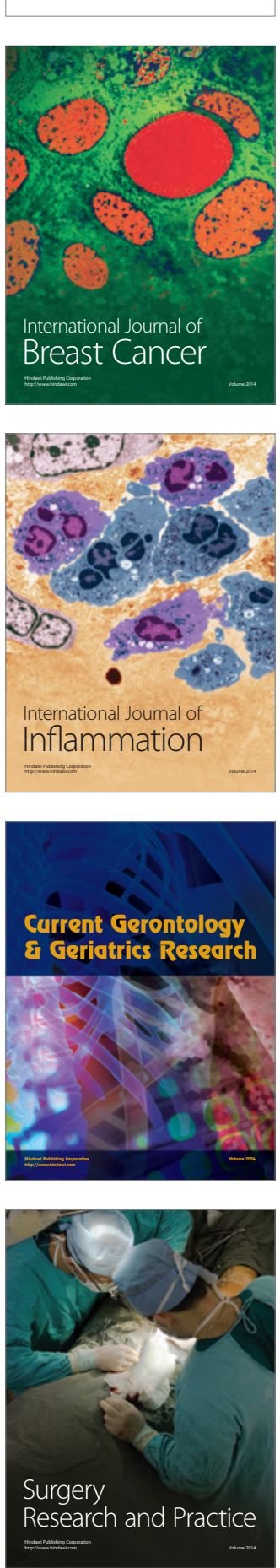

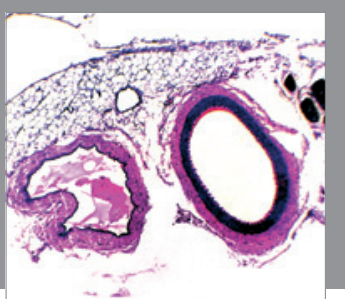

International Journal of Hypertension
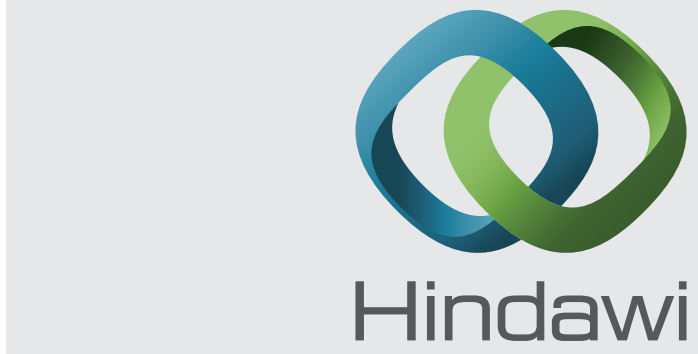

Submit your manuscripts at http://www.hindawi.com
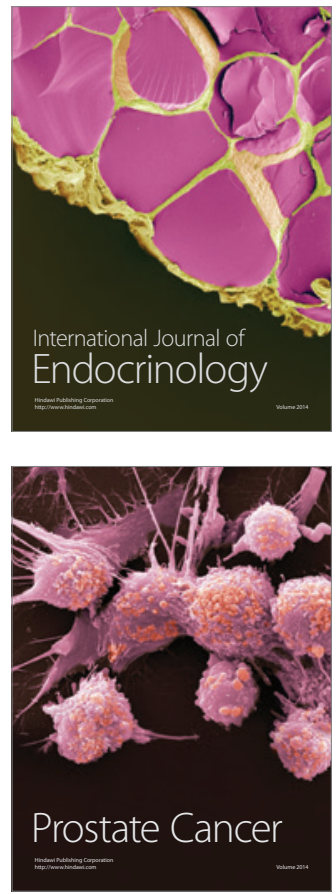

The Scientific World Journal
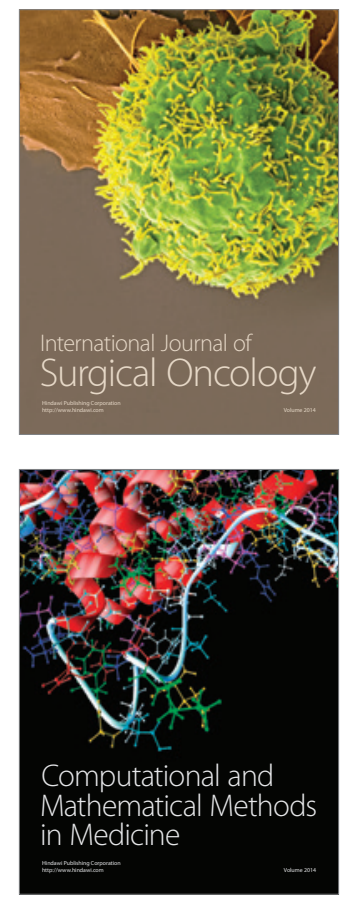
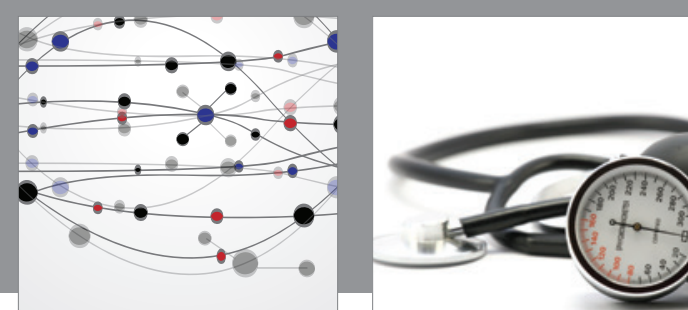

Nursing

Research and Practice

Research and Practice
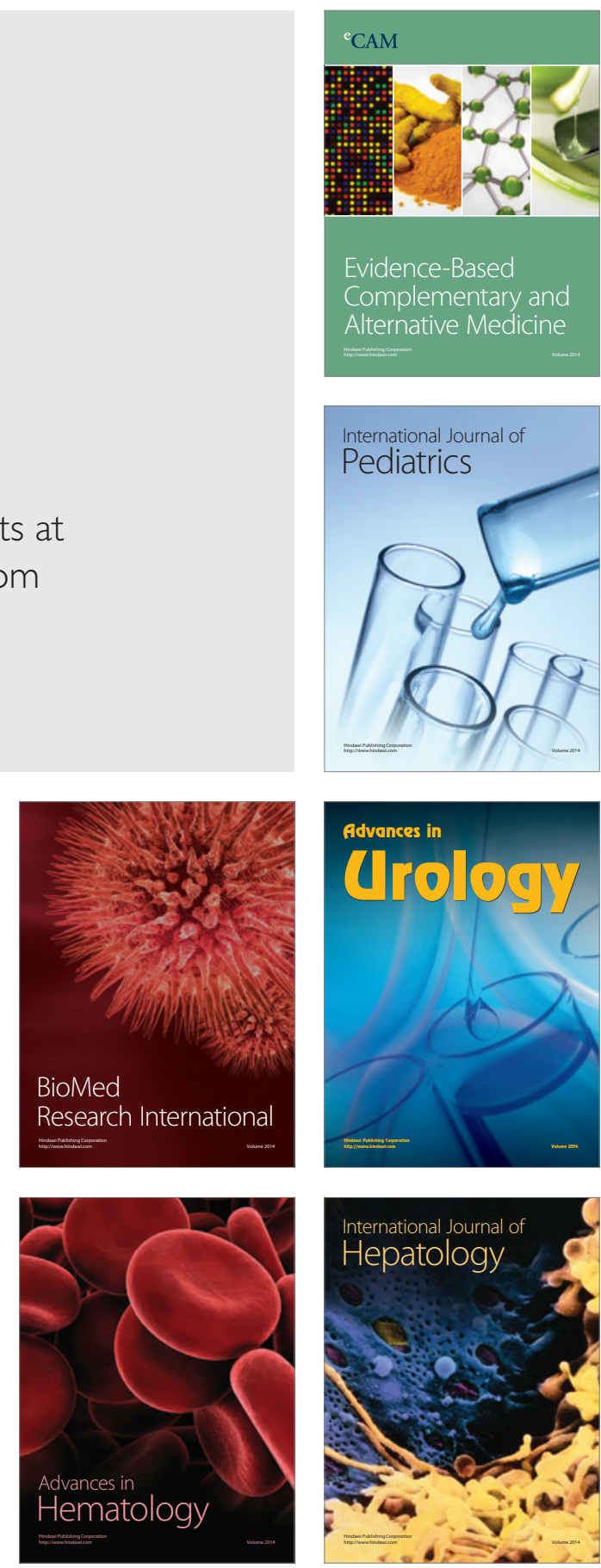
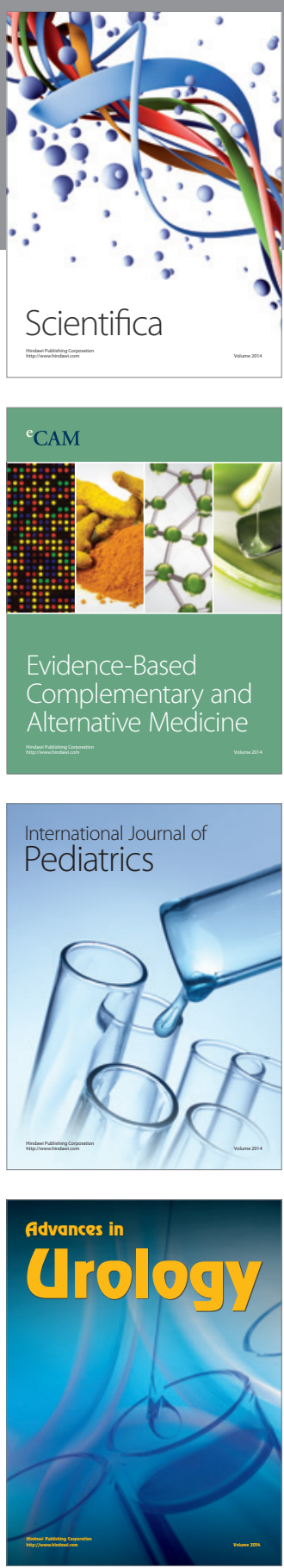

Scientifica

Evidence-Based

Complementary and

Alternative Medicine

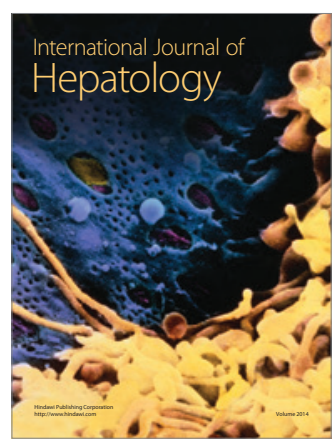

